\title{
CMEARTICLE Management of child abuse
}

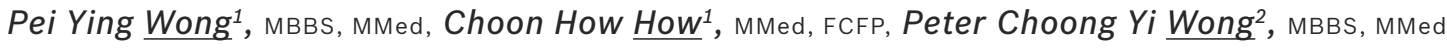

Daniel, who was exceptionally quiet for a typical five-year old child, came to see you for high fever. When you auscultated his chest, you noticed multiple bruises over his body and linear bruises of different ages across his legs. You also observed the poor eye contact Daniel had with his father and the way Daniel withdrew when his father moved. You asked Daniel and his father about the bruises and how Daniel is like at home.

\section{WHAT IS CHILD ABUSE?}

Child abuse is defined as any act of omission or commission by a parent or guardian that would endanger or impair the child's physical or emotional well-being, or that is judged by a mixture of community values and professionals to be inappropriate. ${ }^{(1)}$

\section{WHY DOES IT MATTER?}

An eminently preventable 'disease', child abuse causes significant morbidity and mortality in individuals who can otherwise expect decades of productivity and a healthy life ahead of them. ${ }^{(2)}$ Children are a particularly vulnerable population that requires particular protection. They deserve a childhood free from abuse, where their basic physical, intellectual, emotional and social needs are met. In this article, we discuss the various types of child abuse, the signs of abuse, and the management of child abuse in Singapore.

\section{TYPES OF CHILD ABUSE}

There are four main types of child abuse: (a) physical - occurs when the child is physically injured by non-accidental means (e.g. forceful shaking, deliberate burning, slapping, excessive discipline or physical punishment), whether or not there was any intention to cause injury; (b) sexual - the exploitation of a child or young person for sexual gratification, or any sexual activity between an adult and a child, including exposing a child to forms of sexual acts or pornographic materials; (c) neglect - the deliberate denial of a child's basic needs, where a parent or caregiver fails to provide adequate food, shelter, clothing, medical care or supervision, or forces a child to do things inappropriate for his/her age; and (d) emotional/psychological impairment of a child's social, emotional, cognitive and intellectual development, and/or disturbances in a child's behaviour that result from parental/caregiver behaviours such as persistent hostility, ignoring, blaming, discrimination or rejection of the child. ${ }^{(2)}$

\section{THE SITUATION IN SINGAPORE}

In Singapore, the lead agency against child abuse is the Child Protection Service (CPS) of the Ministry of Social and Family Development (MSF), which was formed in November 2012 with the restructuring of the former Ministry of Community Development, Youth and Sports. MSF bears the statutory responsibility to protect children from abuse and neglect, as spelt out in the Children and Young Persons Act (CYPA). Under the CYPA, any parent or guardian responsible for the ill-treatment of a child or young person may be liable to prosecution. If convicted, the person may be fined up to $\$ 4,000$ and/or sentenced to imprisonment for up to four years. ${ }^{(3)}$ CYPA protects MSF officers and police officers from civil and criminal liability, and informants of suspected cases of child abuse from personal liability, if they are acting in good faith.

In 2012, there were a total of 247 cases of suspected child abuse investigated by MSF.(4) Physical abuse remains the dominant form of abuse, accounting for $60 \%$ of the total number of MSF child abuse investigations in 2012. Sexual abuse figures have gradually increased over the years, making up 30\% of the total number of investigated cases in 2012. Cases of physical neglect and emotional abuse make up the remaining $10 \%{ }^{(4)}$

Hospitals and other medical centres form the largest source of referrals of suspected cases of child abuse.(4) Primary care physicians comprise the important front line for early detection and referral of suspected cases of child abuse, providing timely intervention to ensure the well-being of the child, as well as prevention of further abuse.

\section{WHO ARE AT RISK OF CHILD ABUSE?}

Victims of child abuse are found in all sections of society, spanning all socioeconomic strata and racial groups. Child abuse can occur independent of household income, religious affiliation, educational qualifications of the parent/caregiver,

\footnotetext{
${ }^{1}$ SingHealth Polyclinics - Sengkang, ${ }^{2}$ Department of Emergency Medicine, KK Women's and Children's Hospital, Singapore

Correspondence: Dr Wong Pei Ying, Family Physician, SingHealth Polyclinics - Sengkang, 2 Sengkang Square, Sengkang Community Hub, \#01-06, Singapore 545025. wong.pei.ying@singhealth.com.sg
} 
or profession of the parent/caregiver - children of doctors and lawyers have also been known to be victims. However, data gathered on child protection cases does indicate that there are factors that put a child at higher risk (Table I). ${ }^{(3)}$

\section{COMMON PITFALLS IN THE RECOGNITION OF CHILD ABUSE}

\section{Not having a high index of suspicion for child abuse}

Injuries that cannot be easily explained or are inconsistent with the reported mechanism of injury, or the presence of particular injury patterns (Table II), should raise the suspicion of possible child abuse. $^{(5)}$

\section{Focusing only on the presenting complaint and missing the warning signs of abuse}

A history of repeated consultations for injuries should also raise the suspicion of possible child abuse. Additionally, a child who shows signs of poor hygiene, constant tiredness, and failure to thrive may be a victim of neglect. Other warning signs include medical needs not being attended to, and a history of being left unattended for long periods of time when it is not appropriate with respect to the age and needs of the child.

\section{Not paying sufficient attention to what children say, and how they look and behave}

Observing the interaction between the child and his/her parents/caregiver is important. In children suffering from physical abuse, a fear of contact with the parent/caregiver may be displayed. Other abnormal behavior may include aggression and/or withdrawal in the child. Emotional/ psychological abuse, while difficult to detect, can undermine the healthy development of a child. The child may show signs of depression, developmental delay, low self-esteem, as well as sleeping and eating problems.

\section{Fear of discussing potentially sensitive issues}

It may be difficult to obtain a full history from the parent/ caregiver with regard to suspected child abuse. A private setting and a nonjudgemental approach may help the parent/ caregiver open up to the physician.

\section{REASONABLE CORPORAL PUNISHMENT OR CHILD ABUSE?}

Corporal punishment (physical punishment where pain is inflicted for discipline) in the domestic setting is prohibited in a number of countries (e.g. Germany, Norway, Sweden, New Zealand). In such countries, a parent who canes or spanks his/her child would fall foul of child abuse laws. However, domestic corporal punishment is lawful in Singapore, as in the United States (with the exception of Delaware, which outlawed it in 2012), the United Kingdom and Australia. ${ }^{(5-7)}$

Cultural differences with regard to corporal punishment are familiar to most of us. In the United States, there is substantial
Table I. Factors associated with a higher risk of child abuse.

Factors associated with a higher risk of child abuse include:
- Parent/caregiver has a poor understanding of the child's
developmental needs
- Parent/caregiver feels fatigued, overwhelmed or unable to
cope with the child's behaviour
- Parent/caregiver has unrealistic expectations of the child,
including school performance
- Cultural beliefs that result in emotional rejection of the child
- Family crisis, such as financial stressors, marital conflicts,
substance abuse or mental health concerns
- Child has behavioural issues or special needs, such as autism
spectrum disorder or physical disability

Table II. Injury patterns suggestive of child abuse.

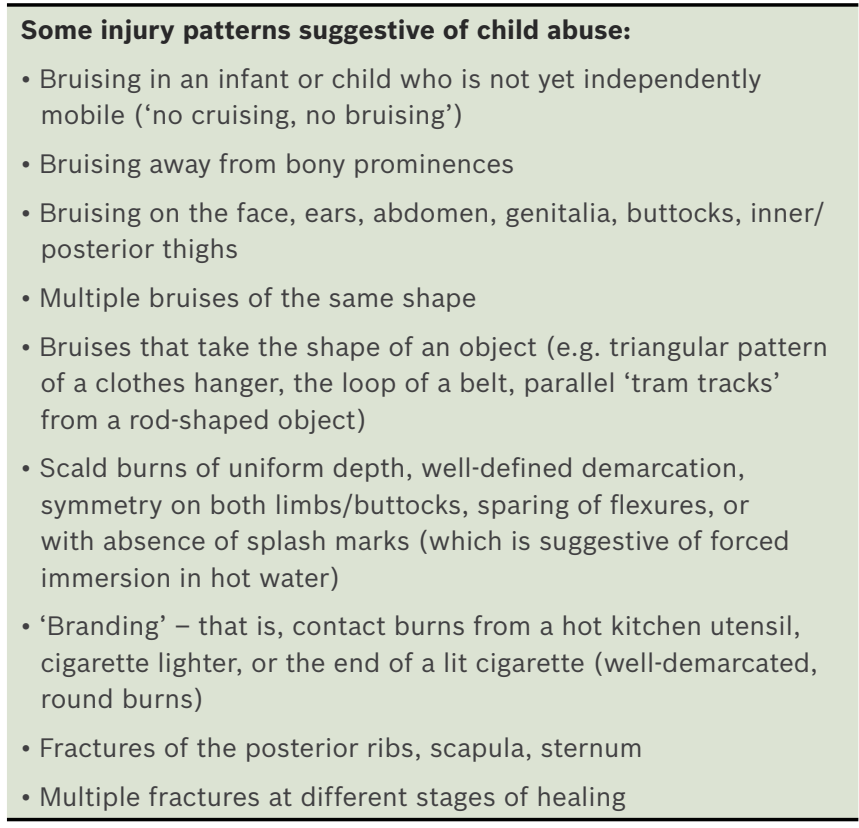

literature about 'culturally competent' practice in child maltreatment management, including special considerations when working with migrant populations. It is, however, not always easy to differentiate between reasonable corporal punishment and child abuse. Generally, in societies where corporal punishment is considered acceptable, there is the societal and professional consensus that reasonable corporal punishment should not: (a) involve excessive force, (b) be unpredictable or carried out in a fit of anger, (c) involve inappropriate implements such as a clothes hanger or a metal rod, (d) involve inappropriate parts of the body such as the face, neck or genitalia, and (e) cause significant injury.

It is always helpful to alert CPS in case of doubt, for example in a child with extensive cane marks, as CPS will have the resources to conduct home visits, and in the best interests of the family and child, link them to the necessary relevant community resources.

\section{MANAGEMENT OF CHILD ABUSE}

The management of child abuse in Singapore is summarised in Fig. 1. To report a case of suspected child abuse, one can call 
Table III. Avenues available for the reporting of suspected cases of child abuse.

\begin{tabular}{ll}
\hline Avenue & Contact number \\
\hline Child Protection Service Helpline & 18007770000 \\
- Mon-Fri: $8.30 \mathrm{am}-5.00 \mathrm{pm} ;$ & \\
$\quad$ Saturdays $8.30 \mathrm{am}-1.00 \mathrm{pm}$ & \\
Police & 999 \\
- Go to the Neighbourhood Police & \\
$\quad$ Post/Centre, or call the police & \\
\hline
\end{tabular}

Table IV. List of helplines and resources available to the public.

\begin{tabular}{ll}
\hline Resource & Contact number \\
\hline ComCare Call & 18002220000 \\
Family Violence Specialist Centres: & \\
- PAVE (Promoting Alternatives to Violence) & 65550390 \\
- TRANS Safe Centre & 64499088 \\
- Care Corner Project StART & 64761481 \\
$\quad$ (Stop Abusive Relationships Together) & \\
\hline
\end{tabular}

either the MSF or the police (Table III). If there are significant injuries, or if the child requires urgent medical attention, the child should also be referred to either the Children's Emergency Department of KK Women's and Children's Hospital or the National University Health System. Whenever possible, parents should be present with the child at the hospital. It is often helpful to truthfully explain to the parents that the child needs further evaluation (sometimes including blood tests to rule out bleeding tendencies that may cause easy bruising) and management in a hospital.

A child referred to the Children's Emergency Department for suspected child abuse or non-accidental injury would be examined for careful documentation of injuries. He/she may require admission to the hospital for further investigation or treatment, or to ensure his/her safety while awaiting investigation by medical social workers, the police or CPS.

\section{PREVENTIVE MEASURES AND RESOURCES FOR THE PUBLIC}

\section{Advise parents}

Children with challenging behaviours are at increased risk for abuse by parents/caregivers. Advice that can be given to parents/caregivers includes the following:

- establish firm and clear rules with the child;

- give clear and calm instructions;

- be consistent; and

- seek assistance from school counsellors, child psychiatrists/ psychologists, or social workers at Family Service Centres or counselling centres.

\section{Teach children how to prevent sexual abuse}

Parents, teachers and care providers can:

- help children learn about parts of their bodies, and educate them that some parts are private and should not be touched by others, except carers while toileting or cleansing;

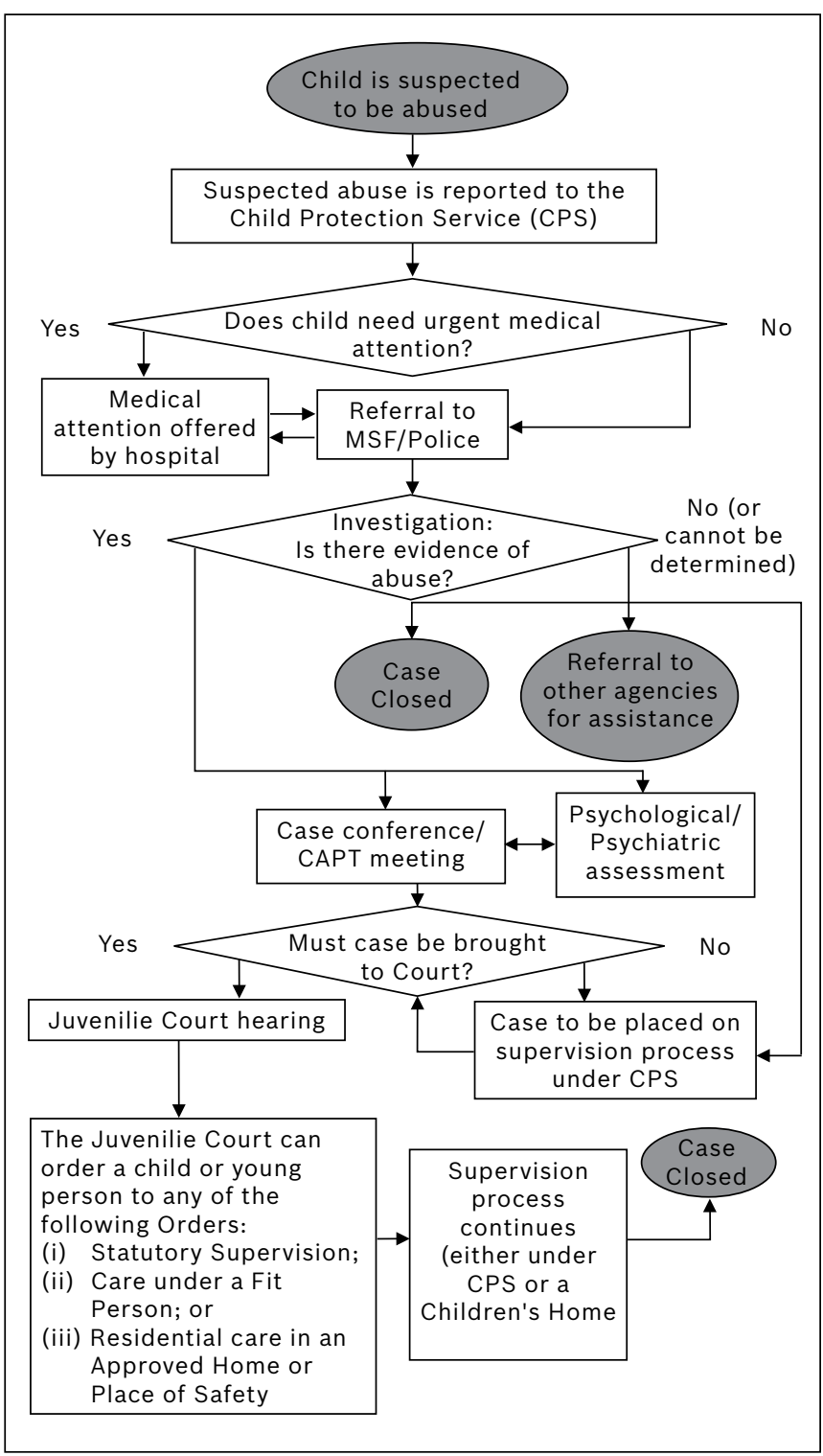

Fig. 1 Flowchart summarises the management of child protection in Singapore. ${ }^{(3)}$ CAPT: Child Abuse Protection Team; MSF: Ministry of Social and Family Development

- teach children that they have a right to refuse anybody's touch that makes them uncomfortable;

- teach children to inform a trusted adult about any such incidents and not to keep it a secret.

Helplines and other resources available to the public are listed in Table IV.

You referred Daniel to the Child Protection Service, which conducted a series of home visits to assess Daniel in his home environment. The team from the Child Protection Service identified that Daniel's father was recently retrenched and had difficulties coping with his anger. Family counselling and anger management therapy were organised for the whole family and Daniel's father, respectively. The team was able to link the family with the Community Development Council, which helped Daniel's father find alternative employment. 


\section{TAKE HOME MESSAGES}

1. Primary care providers play an important role in the early detection, reporting and intervention of child abuse cases.

2. CYPA protects MSF officers and police officers from civil and criminal liability, and informants of suspected cases of child abuse from personal liability, if they are acting in good faith.

3. There are various types of child abuse - physical, sexual, neglect and emotional/psychological. Any child may be a victim of one or more types of abuse.

4. Primary care providers need to be mindful of factors that increase the risk of child abuse, such as family stressors and caregivers who have difficulty coping with a child's behaviour.

5. Primary care providers should be vigilant for injuries that raise the suspicion of child abuse.

6. Primary care providers should know the available resources for reporting and managing child abuse.

\section{ABSTRACT}

Children deserve a childhood free from abuse, where their basic physical, intellectual, emotional and social needs are met. Child abuse is defined as any act of omission or commission by a parent or guardian that would endanger or impair the child's physical or emotional well-being, or that is judged by a mixture of community values and professionals to be inappropriate. A total of 247 cases of suspected child abuse in Singapore was investigated in 2012. Physical abuse, sexual abuse, and physical neglect or emotional abuse accounted for $60 \%, 30 \%$ and $10 \%$ of these cases, respectively. Primary care providers play an important role in the early detection and referral of child abuse cases, which enable timely intervention to ensure the well-being of the child and prevent further abuse. Hospitals and other medical centres form the largest source of referrals of suspected child abuse.

Keywords: child neglect, child maltreatment, child mistreatment, domestic violence

\section{REFERENCES}

1. LG Goh. Management of child abuse in Singapore. Singapore Fam Physician 2011; 37:17-24.

2. Ministry of Community Development, Youth and Sports. National Standards for Protection of Children. Singapore: Ministry of Community Development, Youth and Sports, 2002.

3. Ministry of Community Development, Youth and Sports. Protecting Children in Singapore/Rehabilitation and Protection Division, Singapore: Ministry of Community Development, Youth and Sports, 2005.

4. Ministry of Social and Family Development. Child Abuse Investigations. In: Child Abuse Investigations - Ministry of Social and Family Development [online]. Available at: http://app.msf.gov.sg/Research Room/ResearchStatistics/ChildAbuselnvestigations.aspx. Accessed October 10, 2013.

5. Child Welfare Information Gateway. What is Child Abuse and Neglect? Recognizing the Signs and Symptoms. Washington: Children's Bureau, U.S. Department of Health and Human Services, 2013.

6. Smith A. Nonaccidental injury in childhood. Aust Fam Physician 2011; 40:858-61.

7. Coleman DL, Dodge KA, Campbell SK. Where and how to draw the line between reasonable corporal punishment and abuse. Law Contemp Probl 2010; 73:107-66. 


\section{SINGAPORE MEDICAL COUNCIL CATEGORY 3B CME PROGRAMME}

\section{(Code SMJ 201310A)}

1. Child abuse is defined as any act of omission or commission by a parent or guardian that would endanger or impair the child's physical or emotional well-being.

2. Child abuse has a significant immediate impact on a child, but the child usually grows out of it.

3. Child abuse is eminently preventable.

4. Naughty children do not deserve a childhood free of abuse, where their basic physical, intellectual, emotional and social needs are met.

5. Physical abuse occurs when the child is physically injured by non-accidental means (e.g. forceful shaking, deliberate burning, slapping, excessive discipline or physical punishment), whether or not there was intention to cause injury.

6. Sexual abuse is rare and does not happen in Singapore.

7. Exposing a child to forms of sexual acts or pornographic materials is considered sexual abuse.

8. Child neglect is the deliberate denial of a child's basic needs.

9. A parent has the right to refuse any medical treatment, even if its life- or limb-saving, for his/her child, and cannot be reported to the Child Protection Service (CPS).

10. When in doubt of possible emotional or psychological abuse, it is helpful to notify CPS, so that further assessment of the child in his/her home environment can be carried out.

11. In Singapore, the lead agency against child abuse is the CPS under the Ministry of Social and Family Development, which was formed in November 2012 from the restructuring of the former Ministry of Community Development, Youth and Sports.

12. The Children and Young Persons Act (CYPA) states that any parent or guardian responsible for the ill-treatment of a child or young person may be liable to prosecution.

13. CYPA protects informants of suspected child abuse from personal liability, if they are acting in good faith.

14. Child abuse cases are present in Singapore, and the number of sexual abuse cases have gradually increased over the years.

15. Hospitals and clinics seldom refer suspected cases of child abuse to the authorities.

16. Primary care physicians comprise the important front line for early detection and referral of suspected cases of child abuse, providing timely intervention to ensure the well-being of the child and prevention of further abuse.

17. Child abuse only occurs in poorer or broken families with parents of low educational levels.

18. A history of repeated consultations for injuries, signs of poor hygiene, constant tiredness, failure to thrive, and/or missing primary childhood vaccinations for long periods in a child are warning signs of possible child abuse.

19. A full history from the parent/caregiver with regard to non-accidental injuries might be easier with sufficient privacy and a nonjudgemental approach.

20. When significant injuries have been diagnosed, or if the child requires urgent medical attention, the child should be immediately referred to the Children's Emergency Department of KK Women's and Children's Hospital or the National University Health System.

\section{Doctor's particulars:}

Name in full

MCR number

Email address

\footnotetext{
SUBMISSION INSTRUCTIONS:

(1) Log on at the SMJ website: http://www.sma.org.sg/publications/smjcurrentissue.aspx and select the appropriate set of questions. (2) Provide your name, email address and MCR number. (3) Select your answers and click "Submit".

RESULTS:

(1) Answers will be published in the SMJ December 2013 issue. (2) The MCR numbers of successful candidates will be posted online at the SMJ website by 27 November 2013. (3) Passing mark is $60 \%$. No mark will be deducted for incorrect answers. (4) The SMJ editorial office will submit the list of successful candidates to the Singapore Medical Council. (5) One CME point is awarded for successful candidates. 